\title{
Effect of Information Technology on the Human
}

\author{
Yuhan Guo ${ }^{1 *}$ \\ ${ }^{1}$ Graduate management Team, Logistics University of PAP, Tianjin, China \\ *Yuhan Guo, E-mail: 752191130@qq.com
}

Received: June 11, 2017

Accepted: June 21, 2017

Online Published: June 22, 2017

doi:10.22158/rem.v2n3p98

URL: http://dx.doi.org/10.22158/rem.v2n3p98

\begin{abstract}
With the continuous development of information technology, information technology has infiltrated the divers industries of society. The impacts of information technology on social economic management including human resource management have become stronger. This paper starts with the essence of information handling and analysis of information technology, explores the influence of information technology on the model of human resource management, and builds the closed loop model modern human resource management supported by information technology. Meanwhile, the paper analyzes the effects of closed loop model of modern human resource management supported by information technology, and the requirements resulting from information technology application in the future to help people to understand human resource management from the perspective of information technology application.
\end{abstract}

\section{Keywords}

information technology, human resource management, closed loop model of human resource management, effect analysis

\section{Human Resource Management and Information Technology}

In order to maximize the efficiency, the collaboration of all links and various departments in enterprises and organizations is critical; the daily capital flow, logistics and information flow should be kept open to guarantee the decision-making and the adjustment of the overall strategy. At the same time, we should notice that when these strategic arrangements are reasonable, the most unstable factor and the most secure factor is the human resource management. The human resource management runs through every link, because each link is controlled and affected by people. Therefore, in a company, the personnel appointment, training, staff motivation, staff monitoring and so on are all related to the lifeblood of the overall operation of the enterprise. It can be said that the human resource management is the core element of the enterprise management. Without its optimization, the optimization in other aspects will be limited. Information technology refers to all natural and social technologies, including the skills of information workers, information-based instruments of labor and information-based objects of labor, and it also 
relates to the management systems, method systems, solutions, systems integration, services and other aspects of information technology. Modern information technology is a kind of technology which is different from agricultural technology, industrial technology, energy technology, business technology and other categories of technologies; it refers to the information technology characterized by semiconductor technology, microelectronics technology, integrated circuit technology, communication technology and computer technology from the 1960s. The rapid development of modern information technology has more and more effects on social economic activities, and the impact of modern information technology on the management is becoming more and more significant.

\section{Information Technology's Driving the Changes of the Human Resource Management Pattern}

At the beginning of the 1980s, with the rapid development of information technology mainly in terms of computer technology, especially in the late 1990s, because of the rapid rise of the application of the Internet, the constant reduction of the cost of broadband and the wide universal use of information technology in the field of management, the enterprise management model as well as the human resource management pattern is obviously affected and changed. The essential function of information technology is to achieve the collection, storage, processing, release, transmission and application of information. Therefore, the scientific management of human resources cannot be separated from good information processing and information management. From the procedure of the handling function of the management information, the core data and information of human resource management includes four parts: human resource's analyzing data and updating the mechanism of guidance information, human resource's updating data and developing the mechanism of guidance information, human resource's developing data and motivating the mechanism of guidance information as well as human resource's motivating data and balancing the mechanism of guidance information. The main purpose of each part of main human resource management is different; human resource's analyzing data and updating the mechanism of guidance information is mainly for achieving the resource supply, resources reorganization, resource optimization, resource elimination and resource flow; human resource's updating data and developing the mechanism of guidance information is for achieving the advance of manpower, guidance and communication, tools supply, process reengineering, role transformation and so on; human resource's developing data and motivating the mechanism of guidance information is to achieve progress sharing, value promotion, long-term incentive, right and responsibility adjustments, late evaluation and the like; the purpose of human resource's motivating data and balancing the mechanism of guidance information is the same as that of human resource's analyzing data and updating the mechanism of guidance information, to achieve the resource supply, resources reorganization, resource optimization, resource elimination and so on, thereby realizing the closed-loop process of human resource management, which is represented with the process model as shown in Figure 1: 


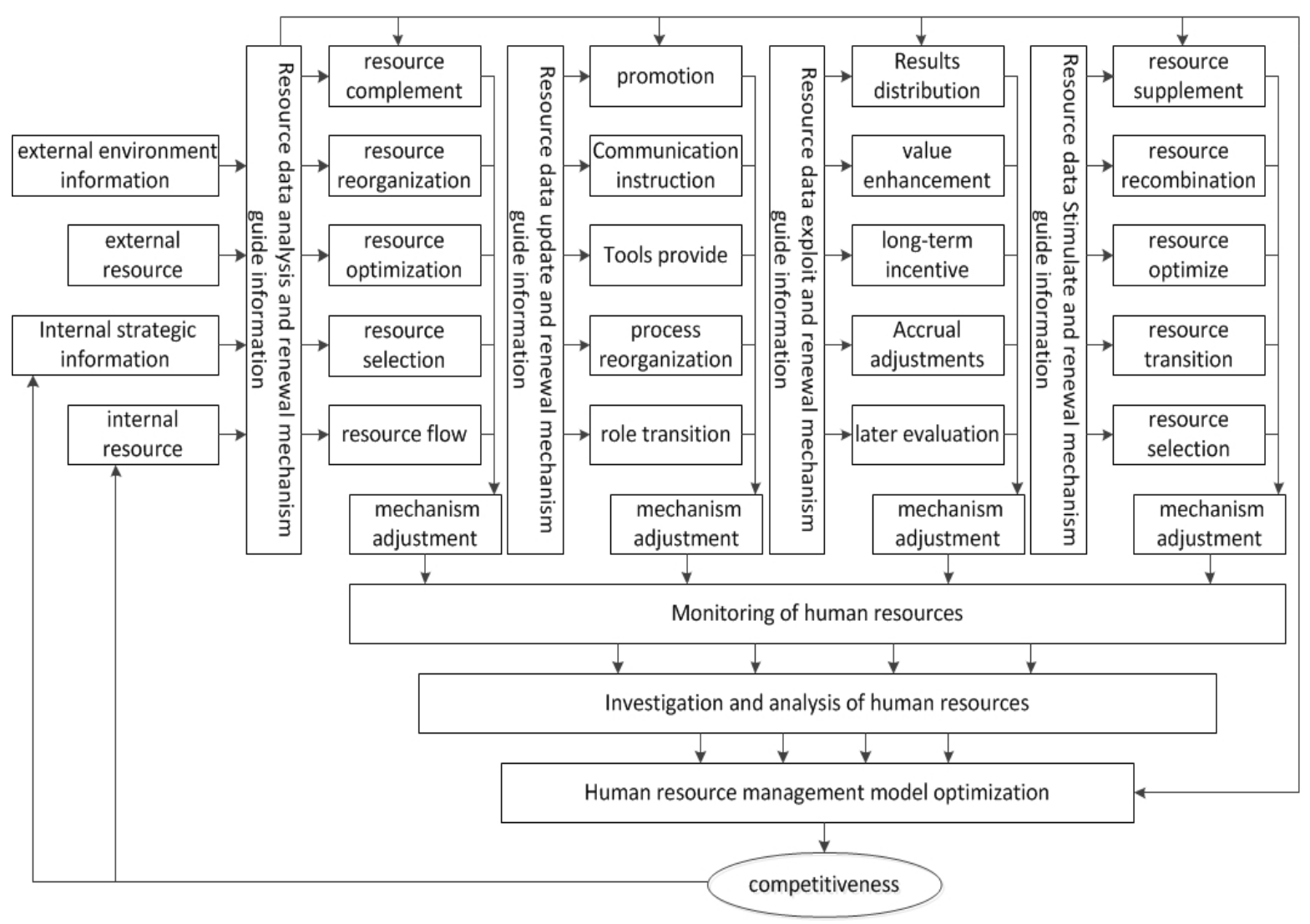

Figure 1. The Closing Process Diagram of Human Resource Management

Each part of the above process model essentially corresponds to the specific business operation and management actions in human resource management. For example, the corresponding management actions of human resource's analyzing data and updating the mechanism of guidance information are the recruitment and selection, quality evaluation, mobility, demission and job analysis; the corresponding management actions of human resource's updating data and developing the mechanism of guidance information are training management, electronic journals, daily work, cultural construction, career planning, etc.; the corresponding management actions of human resource's developing data and motivating the mechanism of guidance information are the salary and welfare management, stock option allocation, award and punishment, power and responsibility division, logistics service and security, etc.; the corresponding management actions of human resource's motivating data and balancing the mechanism of guidance information are systematic management, contract management, dispute management, complaint management, employee's suggestions and so on. Therefore, with the support of information technology, the closed-loop model of modern human resource management can be showed in Figure 2 as follows: 


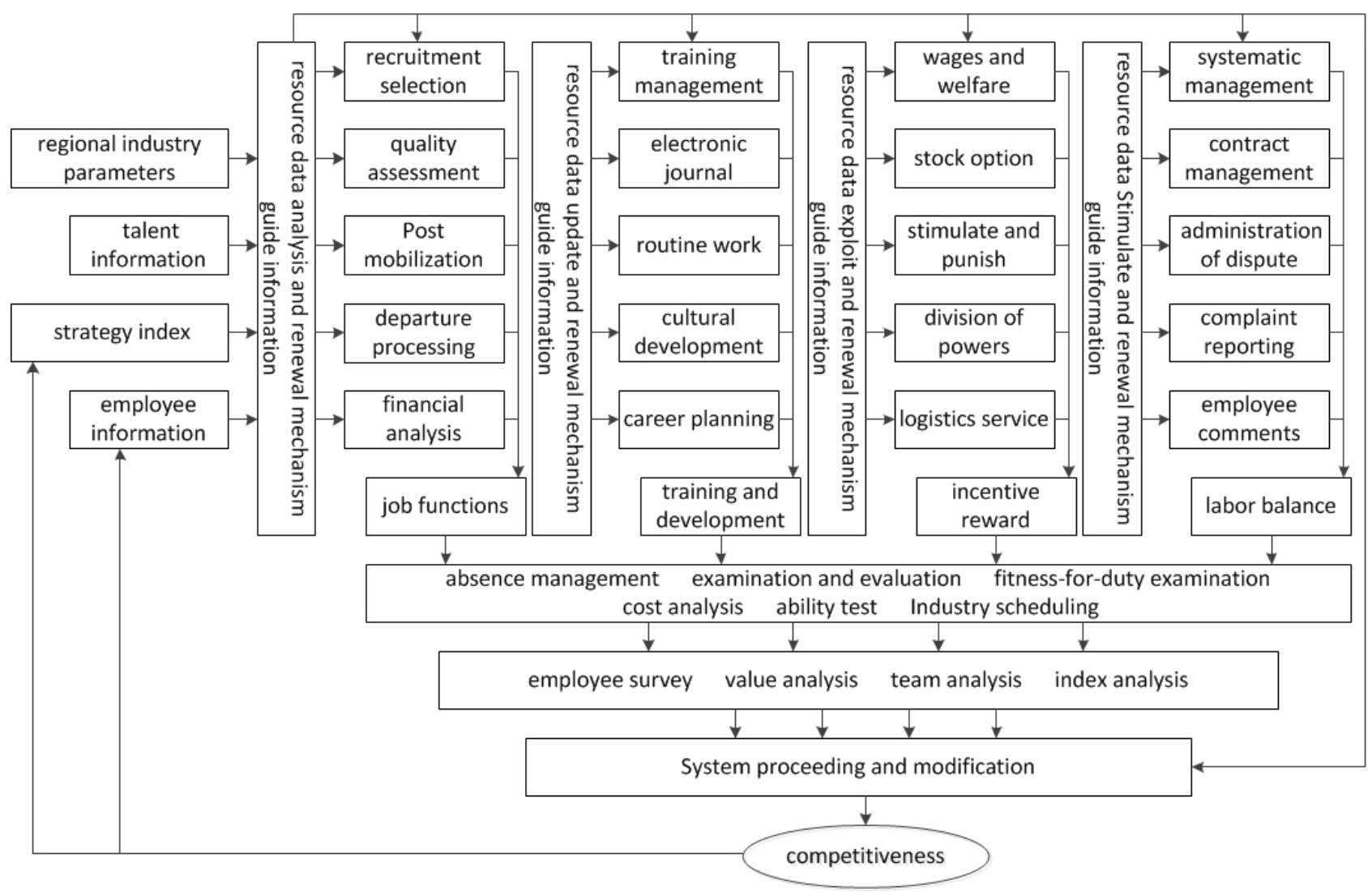

Figure 2. The Closing Pattern Diagram of Modern Human Resource Management

The human resource management model supported by information technology will be obviously a closed-loop optimization and improvement process. It is a platform for both external and internal information processing and analysis.

\section{Effect Analysis of the Closed-Loop Model of Human Resource Management Supported by Information Technology}

In the closed-loop model of human resource management supported by information technology, the performance of human resource management will be significantly improved.

\subsection{The Work Efficiency of Human Resource Management Department is Improved}

The main factors that affect the work efficiency of human resource management department include monthly payroll accounting and processing, staff's attendance and vacation, employees' information management and other business contents. These matters tend to continuously occupy a plenty of time of human resource management personnel. The manual operation is inefficient and error-prone, so the application of information technology in human resource management will greatly reduce the proportion of the time for routine work to the occupied time of human resource management personnel, enabling managers to be free from the routine work. Information technology emphasizes the employees' self-service. If the employee's personal information has changed, he can update his information on the 
information technology platform. After a certain approval, the program will take effect. Similarly, training, holiday requests, reimbursement and other day-to-day administrative affairs can also go through the similar procedure. This not only reduces the workload of human resource management personnel for data acquisition, confirmation and update, but also better ensures the quality of data and the speed data updating, which greatly improves the efficiency of human resource management department beyond doubt, so that they will have more time to think about the problem of strategy layers.

\subsection{Business Processes in the Department of Human Resource Management Are Regulated}

When the human resource managers are free from the complicated administrative affairs, they hope to regulate the business process of the operation system of human resources. The recruitment process, performance management process, staff training and development process, employee career planning, demission and so on are taken into account by human resource managers. Information technology will combine the distributed information about human resource management together and analyze to automate and optimize the business process of human resource management, making information flow accelerate and more comfortable, as well as making the integration of the working process and the business process of human resource management processes as well as the line function closer. Through the application of information technology, not only the job function of human resource management department can be fully covered and clearly divided, but also the optimized business process can be reflected in the system. The day-to-day business of human resource management such as the appointment and dismissal of leaders, retirement, deployment, resignation and so on can be done according to the corresponding model of standard process design. Inquiry, statistics, the production of the personnel roster, statistical statements, the leadership's examination and approval as well as other processes can also be carried out in the information technology network.

\subsection{The Cost of Human Resource Management Has Been Effectively Reduced}

Through the application of information technology. For example, in terms of staff training, staff can get training "online" whenever and wherever possible, which can save time and reduce travel costs as well as reduce the cost of training. In terms of evaluation, through the network, managers at different levels can quickly receive the regularly submitted work reports from the subordinated of various regions, and they conduct assessment, guidance and supervision, so that the cost can be greatly reduced.

\subsection{The Participation in Human Resource Management is Guaranteed}

For the executives in the enterprises, they can check the allocation of the enterprise human resources, the states of key employees, the analysis of the human resource management cost, staff performance and so on. Senior decision-makers can get all kinds of assistances for making decision in terms of the conduct index of human resource and for direct online decision-making; for mid-level managers, namely the line managers, the information technology platform of human resource management is the working platform for participating in the human resource management activities. Through this platform, the line managers can manage the employees in their departments online. For example, they can check the personnel information of all the staff within scope of authority, as well as examine and approve staff training, 
vacation, demission and other processes online; the general employees can online check business regulations; internal recruitment information, personal monthly salary and previous salaries, personal attendance and vacation, registering for internal training courses, application for leave and vacation, online reimbursement, etc.

\section{Requirements of Closed-Loop Human Resource Management Pattern for the Future} Development of Information Technology

In the new closed-loop human resource management pattern supported by information, with the rapid development of economy and the expansion of business needs, new requirements for the future development trend of information technology will be put forward.

\subsection{The Development of Information Technology Needs to be Based on the Platform and Model}

With the further application of information technology in the closed-loop human resource management pattern, the customer demands of different industries and scales vary a lot. How to meet the personalized needs of customers has become an important issue. The operation and development of information technology based on the platform and model have enough flexibility to meet customer needs and the development needs of the closed-loop human resource management pattern.

4.2 The Application of Information Technology Based on the Internet and the New $3 G$ Technology with Total Involvement Will be Applied to the Closed-Loop Human Resource Management Pattern

The IDC statistic data show that by the end of $2006,40 \%$ of the employees in global enterprise had been transferring. With the increase of the mobile workforce in the enterprises, the demands for mobile business applications are also growing. The development of the Internet and $3 \mathrm{G}$ technology will further promote the widespread application of information technology in human resource management, promoting the original simple human resource management to be a process with full participation.

\subsection{The Information Technology Needs to be Based on SOA Architecture and Integrated Application}

The application of information technology in human resource management is not a simple and independent system. From the entire information technology application platform of the enterprises, the information technology systems in human resource management must be closely integrated with external systems. The integrated application of human resource information technology based on SOA architecture has become inevitable in the enterprises.

\subsection{The Information Technology Needs the Cooperation Based on the Workflow Technology}

After the enterprises finish the construction of fundamental human resources data, the next step is to focus on the business process management of human resource. Through the cooperation of various human resource departments, a variety of complex human resource businesses can be quickly completed. The workflow technology is the next key area of the application of information technology in human resource management. With the help of workflow technologies, the enterprises or groups can quickly accomplish the trans-department human resource businesses across the regions, and further standardize the business processes. 


\section{References}

Lian, K. (n.d.). The Enterprise Information and Information Process of Human Resource.

Management. (2005). Review and Prospect of Information Technology, 1.

Yang, M. L. (n.d.). The Application of Information Technology in the Enterprise Human Resources Management. Management Forum, 2002(2).

Zhang, J. H. (2002). Internet and Enterprise Human Resource Management. China Soft Science, 4.

Zhang, L. (n.d.). Human Resource Information System. Dalian: Dongbei University of Finance and Economics. 